Tsutahara, R. (2022). Desemantización verbal desde la perspectiva

de la enseñanza de ELE

RILEX. Revista sobre investigaciones léxicas, 5/I, 119-147

\title{
DESEMANTIZACIÓN VERBAL DESDE LA PERSPECTIVA DE LA ENSEÑANZA DE ELE ${ }^{1}$ \\ VERBAL DESEMANTICIZATION FROM THE PERSPECTIVE OF TEACHING SPANISH
}

\author{
Ryo Tsutahara \\ Universidad de Kyushu \\ tsutahara@flc.kyushu-u.ac.jp
}

\begin{abstract}
RESUMEN
Los verbos más frecuentes suelen tener múltiples usos. En algunos de ellos los verbos están altamente desemantizados y funcionan como verbos de apoyo, pseudocopulativos o forman parte de perífrasis. En este estudio contemplaremos el fenómeno de la desemantización verbal desde la perspectiva docente. Primero, mostraremos la alta frecuencia del fenómeno y defenderemos la importancia de los usos desemantizados. Después, señalaremos la dificultad de manejar los usos desemantizados para los no nativos. Además, repasando los estudios acerca de estos usos realizados en el ámbito de la lingüística, propondremos una metodología y estrategia para enseñarlos.
\end{abstract}

Palabras clave: desemantización, colocación, ELE, verbos frecuentes, expresiones formulaicas.

\begin{abstract}
The most frequent verbs tend to have multiple uses. In some of them, the verbs are highly desemanticized and function as light verbs, pseudocopulatives or are part of periphrases. In this study, we will look at the phenomenon of verb desemanticization from a teacher's perspective. First, we will show the high frequency of the phenomenon and point out the importance of desemanticized uses. We will also show the difficulty of handling desemanticized uses for non-native speakers. Then, reviewing the studies on these usages carried out in the field of linguistics, we will propose a methodology and strategy to teach them.
\end{abstract}

Keywords: desemanticization, collocation, ELE, frequent verbs, formulaic expressions.

${ }^{1}$ Este estudio fue financiado por JSPS (Grant-in-Aid para jóvenes científicos B, 17K17698). 


\section{INTRODUCCIÓN}

Las palabras más frecuentes suelen tener un gran número de significados y usos. Por eso, la gran parte de los discursos y textos suele construirse mediante la repetición de las palabras básicas. En el caso del español, aproximadamente un 70\% del lenguaje escrito lo conforman las seiscientas palabras más frecuentes² . Así, el español depende fuertemente de las palabras básicas. Considerando la importancia de estas palabras, impartimos un curso especializado en la polisemia y multifunción de los verbos más frecuentes. El curso consiste en quince clases (90 minutos). Este curso es principalmente para los estudiantes de $1^{\circ}$ y $2^{\circ}$ grado y la mayoría de ellos están en el nivel A1 y A2 y en cada curso hay alrededor de 50 estudiantes. En cada clase, tratamos solo uno o dos verbos y los profundizamos explicando sus significados, usos frecuentes y colocaciones que forman.

A través de esta experiencia docente, confirmamos que se dan algunos usos de comprensión sencilla, mientras que otros resultan difíciles de entender y emplear para nuestros estudiantes. Por ejemplo, en el caso de tener, el significado de posesión se aprende sin problemas como, tengo dos libros. No obstante, los usos no plenos que no denotan posesión presentan cierta dificultad, como en los ejemplos (1) y (2).

(1) Tuve una conversación con ellos.

(2) Tengo la tarea hecha.

Lo mismo ocurre en el caso de dar. El uso básico del verbo, la transferencia, es fácil de entender, como te doy un libro. No obstante, el verbo no la representa necesariamente. Se requiere cierto esfuerzo de comprensión para manejar su uso como en (3).

(3) Di un paseo por el parque ayer.

\footnotetext{
${ }^{2}$ cf. Tsutahara (2018b).
} 
Nuestros estudiantes, de nivel básico, tienden a considerar que el verbo ir es un verbo especializado en la denotación de movimiento, pero, en realidad, esto no es siempre así. Ejemplos como (4) y (5) implican una dificultad de uso mayor para los no nativos.

(4) Hoy ella va muy elegante.

(5) Hoy va a nevar.

Lo común entre los usos en (1)-(5) es que los valores semánticos de los verbos estén reducidos. En (1) y (2), el verbo tener deja de expresar posesión y en (3)-(5), ni dar ni ir mantienen su significado original. Es decir, están desemantizados, perdiendo la mayor parte de su contenido semántico original. Este fenómeno en el que se suprime el significado léxico de un verbo en función de la naturaleza de sus coapariciones se denomina desemantización (lo detallaremos en 2.1.). Cabe señalar que el verbo desemantizado no es totalmente funcional, en el sentido de que no pierde completamente su significado, sino que conserva una cierta carga semántica. Para más información sobre este fenómeno, véase Allan (1998), Alonso Ramos (2004), NGLE §34.11j y Butt (2014). En estos casos, los verbos casi no tienen ningún sentido y solo juegan un papel de complementar los valores acerca del sujeto, el tiempo verbal, el modo, el aspecto, etc.

En este estudio, analizaremos el fenómeno de la desemantización desde la perspectiva docente repasando los estudios acerca de este tema realizados en el ámbito de la lingüística. Más concretamente, intentaremos mostrar la importancia del fenómeno de desemantización en el aprendizaje del español y destacar la dificultad que el fenómeno implica para muchos no nativos. Además, propondremos una estrategia para enseñar los usos desemantizados verbales presentando nuestra experiencia práctica. 


\section{DESEMANTIZACIÓN VERBAL}

En el ámbito de la lingüística y la lexicología, ya hay abundantes estudios dedicados a los usos desemantizados ya vistos y cada uno de ellos tiene su denominación:

tener conversación, dar un paseo: verbo de apoyo ${ }^{3}$

ir elegante: verbo pseudocopulativo ${ }^{4}$

tener $N$ hecho, ir a $V$ : perífrasis

Cada uno de estos usos suele tratarse como un tema independiente. Para comenzar, nos gustaría indicar que los tres usos no son totalmente distintos, sino que resultan de un mismo proceso, la desemantización, que es el que tenemos como premisa de nuestro análisis. Lo común entre ellos es que se trata de verbos que han perdido la mayoría de su carga semántica al combinarse con complementos predicativos.

Por ejemplo, De Miguel (2009, 26) explica que "un verbo de apoyo se define como un verbo con escaso significado predicativo que se combina con sustantivos derivados, con los que se reparte la tarea de predicar ${ }^{5}$." Estos tipos de sustantivos, por denotar eventos y estados, realizan predicaciones por sí solos y por ello, el papel de los verbos se limita al de licenciador verbal. Según la autora, en las construcciones como dar un paseo, las palabras constituyentes se juntan y funcionan como un verbo. En este tipo de construcciones, los sustantivos que se combinan con verbos de apoyo suelen ser eventivos (fiesta, guerra, partido, etc.) o sustantivos derivados de verbos (conversación, paseo, baile, etc.). En estudios como Koike (1992) y NGLE, se define de manera más amplia. Por ejemplo, NGLE los caracteriza como "los grupos verbales semilexicalizados de naturaleza perifrástica constituidos por un verbo y un sustantivo abstracto que lo complementa (\$1.10k)", sin referirse a eventividad

\footnotetext{
${ }^{3}$ Hay otras denominaciones para referirse a este uso verbal como verbo soporte, verbo ligero, y verbo vicario. NGLE defiende que dar, hacer, tomar, tener y echar son los representativos. ${ }^{4}$ También se llama verbo semicopulativo. Los verbos pseudocopulativos se dividen en dos clases según su aspecto léxico: estativo (corresponde a be en inglés) y télico (corresponde a become en inglés). Los pseudocopulativos andar, seguir, continuar son de la clase anterior y los pseudocopulativos como quedar(se), hacerse, ponerse y volverse son télicos.

${ }_{5}^{5}$ El énfasis es nuestro.
} 
de complementos. Según el libro, las construcciones como dar rabia y poner multa se tratan como construcciones de verbo de apoyo. Nótese que los sustantivos en estas combinaciones no denotan eventos. La definición de Del Burgo (1998) es aún más amplia, "nos referiremos a los verbos que forman las expresiones idiomáticas como verbos de soporte (p. 179)”. Así, en el ámbito de la lingüística española, lo que indica el término "verbo de apoyo" varía bastante, pero nótese que coinciden en tratarlo como verbo desemantizado.

Si los verbos de apoyo son verbos transitivos desemantizados, podría explicarse que los verbos pseudocopulativos eran verbos intransitivos desemantizados. Morimoto y Pavón (2007) lo explican como sigue: "Fundamentalmente, ambas clases de verbos están desemantizados, de modo que lo que aportan a la construcción no es un significado léxico, sino determinados matices aspectuales o modales." (Morimoto y Pavón 2007, 10).

La NGLE también lo detalla desde el punto de vista lexicalista empleando el término "gramaticalización": "Los verbos semicopulativos proceden de verbos plenos a través de procesos de GRAMATICALIZACIÓN relativamente similares a los que se estudiaron en las perífrasis verbales (capítulo 28).” (NGLE, 2836).

En cuanto a la perífrasis, García Fernández (2006) también la explica con el término "desemantización".

Desde el punto de vista semántico, las construcciones perifrásticas suelen ser descritas por el proceso de desemantización que experimenta el auxiliar y que puede ilustrarse fácilmente con la oración Va a nevar, donde la forma $v a$ no denota movimiento alguno. (García Fernández, 2006, 21).

La variedad de perífrasis es amplia y varía el grado de la desemantización de cada una de ellas. Por eso, el autor se muestra prudente al proponer una definición unitaria, pero admite que los verbos se desemantizan al combinarse con participios, gerundios o infinitivos. Siendo derivados verbales, estos elementos también tienen características predicativas como sustantivos eventivos o complementos atributivos. 
Como defenderemos en el apartado 5., para enseñar, o aprender eficazmente estos usos verbales, es sumamente ventajoso tener en cuenta que resultan del mismo mecanismo. Esta visión no es irrelevante, puesto que los usos mencionados vienen tratándose como usos desemantizados por diversos autores.

\subsection{DESEMANTIZACIÓN, GRAMATICALIZACIÓN Y AUXILIARIZACIÓN}

En este apartado, profundizaremos en el término "desemantización" y especificaremos lo que vamos a analizar en este estudio, comparándolo con otros términos similares como "gramaticalización" y "auxiliarización". El fenómeno de la gramaticalización es evidentemente similar a la desemantización. En algunos estudios, ambos términos se emplean sin distinción entre ellos, se utilizan como sinónimos. Por ejemplo, como hemos citado en el apartado anterior, NGLE emplea el término "gramaticalización" para explicar los pseudocopulativos. No obstante, evitaremos el uso del término "gramaticalización" para referirnos a los usos verbales que trataremos en este estudio. El motivo es que, en el ámbito general, la gramaticalización suele referirse a los procesos históricos en los que los elementos léxicos se convierten en los funcionales. Se supone que el primer estudio que utilizó el término "gramaticalización" es Meillet (1912), y entre los estudios iniciales que profundizan en ese concepto hay Traugott y Heine (1991), Lehmann (1995). Los casos que se tratan en estos estudios son procesos históricos; ej. el latín ille se convirtió en artículos definidos en las lenguas romances. En este aspecto, los usos desemantizados que trataremos son distintos de las palabras gramaticalizadas en el sentido original. Desde la perspectiva sincrónica, el artículo el no tiene ningún significado léxico y es puramente funcional. En cambio, los verbos que trataremos mantienen su contenido semántico y lo pierden solo cuando se combinan con complementos predicativos -véanse los ejemplos (1) y (2)-. Es decir, se considera que la pérdida sincrónica de su significado viene provocada por factores colocacionales y no se explica como el resultado de un proceso histórico. El término "gramaticalización" suele connotar el posterior 
y por eso evitamos emplearlo. Téngase en cuenta que utilizamos el término "desemantización" para referirnos a los procesos en los que los verbos pierden su significado en función de sus complementos. Un ejemplo es dar, que deja de denotar transferencia y funciona como un verbo de apoyo al combinarse con sustantivos eventivos como paseo.

Tampoco empleamos el término "auxiliarización" (en inglés auxiliation). Aunque Kuteva (2001), que estudia este fenómeno aclara que este proceso es "desemanticization", este concepto es más estrecho. Como representa la denominación, en los estudios de la auxiliarización, se tratan principalmente las combinaciones de verbos desemantizados e infinitivos. Por eso, los verbos de apoyo y pseudocopulativos se consideran no auxiliarizados puesto que estos no se combinan con infinitivos sino con sustantivos eventivos o complementos atributivos. A saber, la auxiliarización es un tipo de desemantización. Por estas razones consideramos que el término "desemantización" es apto para hablar de los fenómenos que tratamos en este estudio.

\section{IMPOR'TANCIA DE LA DESEMANTIZZACIÓN}

En este apartado, señalaremos la importancia docente de tratar los usos desemantizados de los verbos. Para manejar un idioma extranjero, es imprescindible conocer con cierta profundidad la polisemia y múltiples usos de las palabras básicas. Según nuestra investigación, la mayoría de los verbos más frecuentes tienen usos desemantizados. En la tabla siguiente (Tabla 1), resumimos los veinte verbos más frecuentes y sus usos desemantizados. Para los usos desemantizados establecimos cuatro categorías: verbos de apoyo (los verbos que se combinan con sustantivos eventivos y predicativos), verbos copulativos (verbos que se combinan con predicativos atributivos sin añadir ningún contenido aspectual ni modal), verbos pseudocopulativos (verbos que se combinan con predicativos atributivos que les añaden contenidos aspectual o modal) y auxiliares (verbos que se combinan con infinitivos, gerundios, participios y frases preposicionales). El criterio de esta categorización se basa en NGLE. Como 
la misma NGLE y García Fernández (2006) explican, los copulativos y pseudocopulativos son un tipo de auxiliares. Sin embargo, para que el análisis sea lo más detallado posible, distinguimos los (pseudo)copulativos de los auxiliares.

\begin{tabular}{|c|c|c|c|c|}
\hline & Verbo & Frecuencia & Uso desemantizado & Ejemplos \\
\hline 1 & ser & $32,138,461$ & copulativo & Soy José \\
\hline 2 & haber & $18,138,649$ & auxiliar & Me he levantado a las diez \\
\hline 3 & tener & $9,032,329$ & $\begin{array}{l}\text { verbo de apoyo } \\
\text { auxiliar }\end{array}$ & $\begin{array}{l}\text { Tengo mucho miedo } \\
\text { Tengo una mesa reservada }\end{array}$ \\
\hline 4 & poder & $8,169,293$ & auxiliar & Puedo hablar español \\
\hline 5 & estar & $8,018,928$ & copulativo & Están muy preocupados \\
\hline 6 & bacer & $6,806,463$ & $\begin{array}{l}\text { verbo de apoyo } \\
\text { pseudocopulativo }\end{array}$ & $\begin{array}{l}\text { Cada dia hago ejercicios } \\
\text { Se me bizo tarde }\end{array}$ \\
\hline 7 & decir & $4,344,537$ & $\mathrm{n} / \mathrm{a}$ & \\
\hline 8 & ir & $3,869,299$ & $\begin{array}{l}\text { pseudocopulativo } \\
\text { auxiliar }\end{array}$ & $\begin{array}{l}\text { Hoy ella va muy elegante } \\
\text { Va a llover boy }\end{array}$ \\
\hline 9 & ver & $3,443,656$ & pseudocopulativo & Me veo más delgado \\
\hline 10 & dar & $3,394,338$ & $\begin{array}{l}\text { verbo de apoyo } \\
\text { pseudocopulativo }\end{array}$ & $\begin{array}{l}\text { Me gusta dar un paseo } \\
\text { Se da por vencido }\end{array}$ \\
\hline 11 & deber & $2,765,598$ & auxiliar & Deben estudiar mucho \\
\hline 12 & pasar & $2,383,057$ & auxiliar & Pasó a leer otro libro \\
\hline 13 & querer & $1,955,060$ & $\mathrm{n} / \mathrm{a}$ & \\
\hline 14 & poner & $1,909,551$ & $\begin{array}{l}\text { pseudocopulativo } \\
\text { verbo de apoyo }\end{array}$ & $\begin{array}{l}\text { Me puse rojo en el aula } \\
\text { El gobierno no debe poner } \\
\text { ninguna pega. }\end{array}$ \\
\hline 15 & saber & $1,812,654$ & auxiliar & El niño sabe leer \\
\hline 16 & realizar & $1,803,885$ & verbo de apoyo & $\begin{array}{l}\text { Tiene que realizar operacio- } \\
\text { nes bancarias }\end{array}$ \\
\hline 17 & encontrar & $1,731,080$ & pseudocopulativo & Hoy me encuentro fatal \\
\hline 18 & seguir & $1,682,813$ & $\begin{array}{l}\text { pseudocopulativo } \\
\text { auxiliar }\end{array}$ & $\begin{array}{l}\text { Aba sigue enfadada } \\
\text { María sigue escribiéndonos }\end{array}$ \\
\hline 19 & llevar & $1,668,913$ & auxiliar & $\begin{array}{l}\text { Llevo tres años trabajando } \\
\text { aquí }\end{array}$ \\
\hline 20 & llegar & $1,558,786$ & auxiliar & $\begin{array}{l}\text { Al final llegaron a tener seis } \\
\text { bijos }\end{array}$ \\
\hline
\end{tabular}

TABLA 1. Los 20 verbos más frecuentes y su desemantización

(datos del corpus euesTen Ten).

En primer lugar, los dos verbos más frecuentes (ser y haber) son los que están gramaticalizados en el sentido original. A través de los cambios históricos los dos verbos mantienen pocos valores significados y funcionan como 
copulativo y auxiliar puro. Lo mismo va para el caso de poder y estar. Así, en el español, los verbos más frecuentes son los altamente gramaticalizados y la mayoría de los otros verbos en la tabla pueden desemantizarse según sus coapariciones. Por eso, se podría decir que la desemantización era un fenómeno común en el español.

No obstante, parece que no se discute mucho sobre cómo enseñar estos tipos de expresiones (Herrero Ingelmo, 2003; Mitatou, 2011; Sánchez Rufat, 2015) y, por tanto, todavía son pocos los materiales didácticos que las tratan de manera exhaustiva y sistemática. Como mostraremos en la próxima sección, para los no nativos, manejar los usos desemantizados tiene cierta dificultad y por eso consideramos ventajoso desarrollar una metodología para su enseñanza.

\section{DIFICULTAD PARA LOS NO NATIIVOS}

Los usos desemantizados no son fáciles para los no nativos. Para usarlos con fluidez se requiere especial esfuerzo. En este apartado aclararemos los motivos de esta dificultad.

Primero, hay una cuestión de cuasi-polisemia. Hay usos desemantizados que se parecen mucho y hace falta entender la similitud y la diferencia entre ellos. Por ejemplo, el verbo pseudocopulativo hacerse corresponde al inglés become. No obstante, para manejarlo de la forma natural, conocer esta correspondencia no es suficiente. Hay que tener en cuenta también que aparte de hacerse, varios verbos corresponden con become como volverse, quedar(se), ponerse, caer, etc., y cada uno de ellos tiene su unicidad funcional y colocacional $^{6}$. Es decir, los estudiantes tienen que saber en qué situación se puede usar hacerse, en qué situación no se puede usar y, en tales situaciones, qué verbo tiene que emplearse. Entre los verbos desemantizados existe esta

\footnotetext{
${ }^{6}$ Por ejemplo, en el caso del japonés, solo un verbo corresponde con become: なる (naru). Por lo tanto, los nativos de japonés tienen que empezar por entender que en el español varios verbos tienen esta función.
} 
cuestión de cuasi-sinonimia y esto es uno de los factores que dificultan el aprendizaje de los verbos desemantizados.

El otro factor es el hecho de que el criterio de elegir los cuasi-sinónimos dependa altamente de la convención. Véanse los ejemplos erróneos siguientes.

(6) *Me hice loco.

(7) *Se hizo colorado cuando habla en público.

Es fácil indicar que en (6) el verbo tenía que ser volver y en (7) poner, sin embargo, es extremadamente difícil o puede ser imposible explicar por qué tiene que ser así. Si hacerse es become, debe ser posible la combinación hacerse loco. Parece que no hay razón lógica ni semántica que impida la combinación de hacerse con loco y colorado. Como mostraremos en 5.2.1, esto se considera una cuestión de la convención. Por eso parece ser imposible predecir la aceptabilidad de la semántica de los verbos ${ }^{7}$. En otros términos, en el aprendizaje de los usos desemantizados, no se puede contar con un enfoque descendente y la necesidad de memorizar cada una de las combinaciones parece ser inevitable.

El tercer factor es que hay poca analogía con otros idiomas cercanos. Para los estudiantes de español, el inglés es un recurso que les facilita el aprendizaje puesto que hay no pocos cognados y analogías entre ambos idiomas. Esos les sirven a los estudiantes cuyas lenguas maternas son totalmente distintas como el japonés para aprender eficazmente el sistema de léxico y los conceptos gramaticales $^{8}$. Sin embargo, en cuanto a los usos desemantizados, suele haber muchas faltas de correspondencia, incluso falsos amigos, entre ambos idiomas. Por eso, el conocimiento del inglés no les sirve de pista. Hasta ahora, hemos

\footnotetext{
${ }^{7}$ El hecho de que la aceptabilidad de coocurrencia dependa en gran medida de determinadas convenciones parece ser una característica no solo del español, sino de las lenguas naturales en general. Véanse Bybee y Eddington (2006) y Hirasawa (2019) para discusiones más detalladas.

${ }^{8}$ La estrategia de utilizar analogías con el inglés en la enseñanza de la gramática y el vocabulario es muy común. Por lo que sabemos, muchos libros de texto de español de los países de habla inglesa utilizan esta estrategia. Los textos como Barbara Bregstein: Easy Spanish Step by Step son bastante comunes incluso fuera de los países de habla inglesa.
} 
realizado varios estudios comparativos de los usos desemantizados en el español e inglés. En los subapartados siguientes presentaremos algunos de ellos para mostrar las discrepancias de la desemantización entre ambos idiomas.

\subsection{LOS PSEUDOCOPULATIVOS IR Y GO}

En Tsutahara (2020), realizamos un análisis comparativo de ir y go como verbo pseudocopulativo. Dado que los dos verbos son similares en sus usos léxicos, se suponía que los dos verbos, como pseudocopulativos, también mostrarían no pocas similitudes. Sin embargo, no se observó casi ningún punto en común. Para especificar la similitud y la diferencia entre ellos, reunimos los complementos atributivos más frecuentes de los dos pseudocopulativos y empezamos por describir la tipicidad de cada uno de los dos pseudocopulativos. A través del análisis confirmamos que unos complementos se vinculaban con los dos verbos mucho más fuertemente que los otros. Primero veremos el caso de $i r$. Véase la Tabla 2.

\begin{tabular}{|c|c|c|}
\hline & Complemento predicativo & $\begin{array}{l}\text { Frecuencia de coapari- } \\
\text { ción con } \text { ir }\end{array}$ \\
\hline 1 & Dirigido & 25,176 \\
\hline 2 & Acompañado & 21,928 \\
\hline 3 & Destinado & 10,323 \\
\hline 4 & Unido & 4,652 \\
\hline 5 & Encaminado & 4,263 \\
\hline 6 & Vestido & 3,839 \\
\hline 7 & Ligado & 2,562 \\
\hline 8 & Asociado & 2,183 \\
\hline 9 & Precedido & 1,852 \\
\hline 10 & Incluido & 1,496 \\
\hline
\end{tabular}

La alta frecuencia de coaparición de dirigido y acompañado es llamativa. Además, es obvio que estos complementos forman clústeres semánticos. Por ejemplo, dirigido, destinado y encaminado se agruparán en un mismo grupo semántico.

\footnotetext{
9 A partir de aquí, todos los datos en las tablas y las frases de ejemplo que presentaremos fueron extraídos del corpus eues Ten Ten.
} 
(8) Este libro va dirigido a estudiantes de Estructura y Arquitectura de Computadores, y su objetivo es servir de complemento práctico a los textos que cubren los aspectos teóricos de estas materias.

(9) Además del mantenimiento del ritmo, Rivero se ha preocupado por "preservar la riqueza de vocabulario de Shakespeare, y desde luego los dobles sentidos y juegos de palabras, de los que me ocupo someramente en la introducción", si bien no ha querido "incomodar al lector con notas, pues el libro va destinado al amante de la poesía, y no al erudito o al especialista.

(10) "Nuestro interés -ha afirmado la Concejala- va encaminado a poner los elementos necesarios para que estos nuevos talentos puedan desarrollarse en nuestra ciudad y se puedan establecer aquí".

Acompañado, unido, asociado, e incluido se pueden considerar sinónimos ya que todos estos complementos atributivos denotan la relación concomitante.

(11) Los textos van acompañados de dibujos o fotografías, principalmente retratos de artistas.

(12) Junto a la habilidad de Garzón como fotógrafo su éxito va unido a la variedad de trabajos, temáticas que desarrollaba sin desdeñar ningún encargo.

(13) Aunque hasta hace poco no había maneras muy fiables de diagnosticarlos, se consideraba como tal una relación de dependencia patológica del trabajo. Y además, los expertos en rehabilitación de adicciones, aseguran que es frecuente que vaya asociado a otras dependencias como el alcohol, los tranquilizantes o la cocaína, algo que ocurre en el 30\% de los casos.

(14) El postre va incluido en el precio del buffet y se puede elegir entre helado, piña o melón frescos.

Nótese que el valor del aspecto léxico del pseudocopulativo ir se considera "estativo durativo" como defienden Morimoto y Pavón (2007) que"denotan un estado en su transcurso, en su duración, sin hacer mención al estado previo del sujeto" (Morimoto y Pavón, 2007, 31). Por ejemplo, en (11), el pseudocopulativo van puede reemplazarse por están, que es ejemplo de verbo de tipo estativo durativo sin cambiar mucho el significado. Aparte, en cuanto a la modalidad, tampoco está marcado este pseudocopulativo.

En cambio, confirmamos que el uso más frecuente del pseudocopulativo go era aspectualmente télico, denotando cambio de estado o característica. Es decir, es más próximo a become que a be. Además, está modalmente marcado conllevando la modalidad negativa. Por eso, los complementos más frecuentes de go son totalmente distintos de los de ir. Véase la Tabla 3. 


\begin{tabular}{|l|c|c|}
\hline & Complemento predicativo & $\begin{array}{c}\text { Frecuencia de } \\
\text { coaparición con go }\end{array}$ \\
\hline 1 & Wrong & 97,982 \\
\hline 2 & Unnoticed & 26,670 \\
\hline 3 & Live & 22,818 \\
\hline 4 & Viral & 19,241 \\
\hline 5 & Crazy & 18,701 \\
\hline 6 & Strong & 16,009 \\
\hline 7 & Public & 14,490 \\
\hline 8 & Green & 12,387 \\
\hline 9 & Hungry & 11,992 \\
\hline 10 & Bad & 10,706 \\
\hline & TABLA 3. Los complementos predicativos de go. \\
\hline
\end{tabular}

Go mostró una tendencia estadísticamente significativa de combinarse con complementos negativos como wrong, bad, crazy, etc. En otros términos, su función principal es denotar cambios negativos.

(15) More things can go wrong than right in this, and our narrative examines the dynamics through the prism of one foiled attempt.

(16) When the attachment goes bad, heat can't escape, and the cell overheats.

En algunas construcciones, el pseudocopulativo puede considerarse como estativo, pero hasta en este tipo de construcciones su comportamiento es distinto. Según nuestro análisis en el corpus, el verbo es estativo cuando se combina con complementos de tipo un- + participios de pasado como unnoticed, unpunished, unreported, etc. Las construcciones de go y estos complementos, también tienen modalidad indeseada y representan la continuidad de tales estados. Por ejemplo, lo que quiere decir "The news goes unnoticed." es que la noticia "sigue pasando desapercibida", más bien que "pasa desapercibida". Desde el punto de vista de Morimoto y Pavón (2007) este tipo de aspecto se considera "estativo continuativo", que se distingue de "estativo durativo". Las autoras lo definen como siguiente;

[...] los continuativos presuponen que el sujeto que se encontraba en el estado descrito con anterioridad al momento referido por el tiempo verbal. En otras palabras, los continuativos se diferencian de los durativos al indicar la permanencia de un 
estado, cuyo inicio debe situarse en una fase previa a la situación a la que hacen referencia".

A pesar de que la correspondencia semántica entre ir y go es voluminosa, los dos verbos, como pseudocopulativos, se comportan de manera totalmente distinta.

\subsection{LOS VERBOS DE APOYO EN ESPAÑOL E INGLÉS}

En Tsutahara (2018a) llevamos a cabo un análisis contrastivo de los verbos de apoyo en el español: hacer, dar, tomar y tener y sus contrapartes en el inglés: do/make, give, take y have. Especificamos las coapariciones eventivas de estos verbos y comparamos las colocaciones que forman. Intentamos explicar la diferencia y similitud desde esta perspectiva. A diferencia del caso de ir y go, en estos pares, se observaron algunas similitudes, pero también confirmamos notables diferencias.

Entre el par de hacer y do/make, se observó la correspondencia más estrecha. Confirmamos que las contrapartes de los sustantivos eventivos que forman colocaciones con hacer también las forman con do o make como hacer trabajo/do job, hacer esfuerzo/make effort, etc., y viceversa ${ }^{10}$.

Dar y give coinciden en formar colocaciones con los sustantivos que denotan la transmisión de información (consejo/advice, información/information, permiso/permission), beneficiación (ayuda/help, protección/protection, tratamiento/treatment) y contacto físico (abrazo/hug, toque/touch, apretón/squeeze). Estas acciones son las que se dirigen a destinatarios. Por ejemplo, cuando aconsejamos algo, siempre hay alguien que recibe el consejo.

\section{(17) Deme su consejo. gracias. \\ (18) Maybe you can give me an advice ${ }^{11}$ ?}

Se considera que, por esta razón, dar y give tienden a combinarse con sustantivos de estas clases puesto que en su uso léxico, también requieren

\footnotetext{
${ }^{10}$ Battle es excepcional ya que forma una estrecha colocación con do, mientras que hacer y batalla se combinan con poca frecuencia.

${ }^{11}$ Los ejemplos en inglés son de enTenTen20.
} 
destinatarios o complementos indirectos. En el estudio, también indicamos que la estructura argumentativa suele mantenerse en el proceso de desemantización. No obstante, hay diferencias funcionales y colocacionales entre ambos verbos. Dar se combina con más tipos de sustantivos. Es decir, hay clases de sustantivos que se combinan con dar pero no con give. Los sustantivos que denotan la acción de comenzar algo, forman colocaciones con dar pero no con give: dar comienzo, inicio/*give start, beginning ${ }^{12}$ y los sustantivos de movimiento sin meta tampoco se combinan con give, dar paseo, vuelta, paso/"give walk, step ${ }^{13}$.

Tomar y take comparten el mismo significado léxico, acción de coger algo.

(19) La mayor parte de nosotros podemos tomar un libro de una estantería subiéndonos a una escalera, bajarlo y sostenerlo.

(20) It's the kind of place you can take a book and enjoy the calm ambiance, and if it's sunny you can enjoy a seat out in the courtyard to soak up some rays.

No obstante, como verbo de apoyo, juegan distintos papeles. Según la investigación, el uso de take es mucho más fléxible que tomar. A modo de ejemplo, la combinación de take con sustantivos de acción visual es notablemente frecuente, pero tomar no se combina con tales sustantivos: take a look/*tomar una mirada. Aparte de esta clase de sustantivos, la característica de take es la combinación con sustantivos de movimiento. Como hemos señalado en el párrafo anterior, en el español, este papel lo juega dar: take a walk/*_ tomar un paseo). Además, algunas de las colocaciones "take + sustantivos eventivos" corresponden con hacer (ej. hacer fotocopia/take a copy, hacer excursión/take an excursion, hacer escaneo/take a scan)

Tanto tener como have son los únicos verbos de apoyo que se combinan con sustantivos que denotan estados.

\footnotetext{
${ }^{12}$ Give start denota la acción de asustar a alguien.

${ }^{13}$ En inglés, los sustantivos que denotan movimiento suelen combinarse con take (take a step/walk/tour).
} 
(21) Faltan dos días para la graduación, y Jack ( Ben Affleck ) tiene serias dudas acerca de su futuro.

(22) Still, I suppose it's early days yet and I have no doubt that, even as we speak, people are busy documenting their experiences...

No obstante, solo el posterior forma colocaciones con diversos sustantivos dinámicos como have a look, swim, try and read ${ }^{14}$.

Por un lado, los sustantivos dinámicos que se combinan con tener a cierta frecuencia son los únicos que denotan comunicación mutua como tener conversación/fiesta.

El verbo de apoyo más peculiar será echar. Como apuntan NGLE, Montagna (2015) y Tsutahara (2019), el verbo es bastante frecuente y tiene la unicidad colocacional y funcional. Por ejemplo, los sustantivos de acción visual como vistazo, vista, mirada y ojeada solo se combinan con echar. Además, este verbo de apoyo tiene "aspecto impulsivo" (cf. Montagna, 2015) y forma colocaciones con sustantivos como culpa, bronca, piropo, etc. En cambio, el papel de verbo de apoyo de su correspondiente en el inglés throw está bastante limitado como throw a party. Además, hasta sus cognados en las lenguas romances (fr. jeter, it. gettare y pr. jactar) tampoco tienen este uso.

Los idiomas evolucionan afectándose entre sí. Por eso, entre los idiomas cercanos hay muchas analogías. No obstante, dadas no pocas discrepancias de los usos desemantizados, podría considerarse que la desemantización venía desarrollándose en el interior del español. Por eso, desde la perspectiva de los estudiantes, los usos desemantizados tienen que aprenderlos como algo nuevo sin facilitaciones de analogía y sería razonable que los docentes indicaran que era inesperable que hubiera analogías entre los usos desemantizados para prevenir la transferencia negativa.

\footnotetext{
${ }^{14}$ Según Wierzbicka (1982), en Australia e Inglaterra, el uso de have como verbo de apoyo es altamente predicativo y en Estados Unidos, menos. En Australia, por ejemplo, es común decir have a read o have a kick of football es común. En cambio, esta combinación se acepta difícilmente en EE.UU.
} 


\section{5. ¿CÓMO ENSEÑAR LOS USOS DESEMANTIZZADOS?}

Hasta aquí, hemos defendido la importancia y dificultad de aprender los usos desemantizados de los verbos frecuentes. En esta sección propondremos una metodología para enseñarlos.

\subsection{ENSEÑAR EL FENÓMENO DE LA DESEMANTIZACIÓN}

Son muchos los verbos que tienen usos desemantizados. Su variedad es tan amplia que es prácticamente imposible tratarlos todos en la clase y es ineficaz explicar cada uno de ellos de manera independizada. Por eso consideramos apto empezar por señalar que detrás de la amplia variedad de los usos desemantizados hay un mecanismo común: desemantización. Dicho de otro modo, antes de enseñar cada uso desemantizado en concreto es eficiente mostrar que hay complementos de los verbos que tienen carácter predicativo, muchos verbos, especialmente los más frecuentes, pueden combinarse con tales complementos y en tales combinaciones los verbos pierden su significado. Es de notar que los verbos de apoyo, pseudocopulativos y auxiliares resultan de este proceso. El conocimiento profundo de este no solo ayuda a los estudiantes a comprender los usos desemantizados de fondo sino también lo flexible de las actividades lingüísticas de los nativos.

Para explicar el fenómeno, comenzamos por la predicatividad de los complementos, ya que es el gatillo de la desemantización. Especialmente, el hecho de que entre los sustantivos haya eventivos y no eventivos no se sabe bien. Los sustantivos que la llevan muestran distintos comportamientos que los no eventi$\operatorname{vos}^{15}$. Esta clasificación nominal no se suele tratar en las clases de la gramática y la clase del vocabulario es donde debe tratarse este tema. Solemos empezar por la pregunta “¿qué diferencia hay entre las palabras libro y fiesta?”. Aquí incluimos un material que utilizamos para explicar la predicatividad de los sustantivos.

名詞は二種類に分けられる - libro と fiesta どう違う？-

Los sustantivos pueden dividirse en dos tipos ¿Cuál es la diferencia entre libro y manzana?

${ }^{15}$ cf. Grimshaw (1990) y Resnik (2010). 
名詞と一口に言ってもその意味的性質に応じて二種類に分けられること をご存知でしょうか。具体物を表すもの (libro 等) とイベントを表すもの (fiesta 等) の二種類です。スペイン語をより自然に使いこなすにはこの違 いを押さえておく必要があります。Libro と fiestaはどう違うのかを考えて みましょう。

¿Sabías que los sustantivos pueden dividirse en dos tipos según sus propiedades semánticas? Hay dos tipos de sustantivos: los que se refieren a objetos concretos (ej. libro) y los que se refieren a eventos (ej. fiesta). Para utilizar el español con mayor naturalidad, hay que tener en cuenta esta diferencia. Veamos la diferencia entre libro y fiesta:

\begin{tabular}{|c|c|}
\hline Sustantivos eventivos: fiesta & Sustantivos no eventivos: libro \\
\hline Tener lugar, durar 等の動詞と共起する & Tener lugar, durar 等の動詞と共起しづらい \\
\hline 'Se usa con verbos como tener lugar y durar' & 'Se usa poco con verbos como tener lugar y durar' \\
\hline La fiesta duró mucho. & *El libro duró mucho. \\
\hline 所在を表すときは ser & 所在を表すときは estar, hay \\
\hline 'Para expresar su presencia se utiliza ser' & 'Para expresar su presencia se utiliza estar o hay' \\
\hline La fiesta es en la casa de Juan. & El libro está en el bolso. \\
\hline Proceso de, evento de 等の表現と共起する & Proceso de, evento de 等の表現と共起しない \\
\hline 'Se usa con expresiones como proceso de y evento de.' & 'No se usa con expresiones como proceso de y evento de.' \\
\hline En el proceso de la fiesta & En el proceso del libro \\
\hline
\end{tabular}

Después, teniendo la distinción en cuenta, explicamos cómo pierden los significados los verbos. Mostramos a continuación las tablas siguientes para que los estudiantes puedan comprender el fenómeno de manera intuitiva.

\section{Dar 通常の用法 'Dar en el uso normal'} ej. T e doy un libro.

このdoyには以下の情報が含まれています。 en doy están

inclu idos los valores sigu ien tes':

- 主語に関する情報 'valores acerca del su je to’

一 時制に関する情報 'valores acerca del tiem po’

・法に関する情報 ‘valores acerca delm odo’

-「与える」という意味 ‘ignificado de TRAN SFERENC IA ’

\section{Dar 脱意味化用法 Dar en el uso desemantizado} ej. D oy un paseo

このdoy には以下の情報が含まれています。 en doy estánこの paseo には以下の情報が含まれています。 en paseo inclu idos los valores sigu ien tes':

- 主語に関する情報 'valores ace rca del sujeto’

- 時制に関する情報 'valores acerca del tiem po

- 法に関する情報 'valores acerca delm odo’

- 意味は持たない 'no tiene sign ificado léxico' están incluidos los valores siguien tes': 
Además, señalamos que la desemantización es el fenómeno universal. Como apunta Butt (2014) la desemantización es un fenómeno que ocurre en los idiomas en general, incluso en los idiomas no indoeuropeos. Es también ventajoso y facilita el aprendizaje indicar esta universalidad de la desemantización y los ejemplos concretos en la lengua materna de los estudiantes. Por ejemplo, presentamos los casos siguientes.

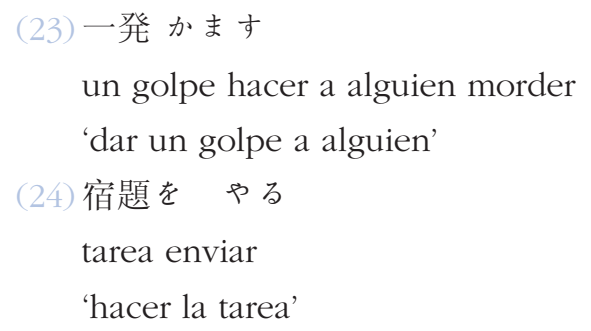

Un chiste como “¿dar un paseo? ¿a quién?” es bastante familiar en las aulas en Japón. Muchos estudiantes suelen pensar que el fenómeno de la desemantización es algo peculiar de español a pesar de que en su lengua materna un verbo con el significado de "hacer a alguien morder" se desemantiza y la mayoría de los japoneses no se dan cuenta de la "peculiaridad" de esta expresión. Claro que esto no es una peculiaridad del español ni un chiste, sino la flexibilidad de combinaciones de las palabras. Desarrollar la conciencia de que la desemantización sí ocurre en la lengua materna de los estudiantes les facilitaría entender la elasticidad del idioma.

\subsection{DAR IMPORTANCIA A LAS EXPRESIONES FORMULAICAS}

Como hemos defendido en el apartado 4, el mayor factor de dificultad del aprendizaje de los usos desemantizados de los verbos será la existencia de cuasisinónimos. En el caso de dar, por ejemplo, no es suficiente tener en cuenta que el verbo funciona como un verbo de apoyo. También hay que entender que otros verbos tienen ese papel y reconocer la diferencia entre ellos. A la hora de tratar los usos desemantizados en la clase, los docentes deberían intentar mostrarles la unicidad de cada uno de los verbos a los estudiantes para que los distingan. 
El hecho que les ayudaría tanto a los docentes como a los alumnos es que para casi todos los verbos en usos desemantizados existen complementos que coaparecen con una frecuencia extremadamente alta, es decir, forman expresiones formulaicas. No es que los verbos desemantizados se combinen con diversos complementos con frecuencia equilibrada. Las combinaciones con estos complementos no solo son útiles por su alta frecuencia de aparición sino porque también reflejan la tipicidad de los verbos y sirven de ayuda para inferir su distribución. Por ejemplo, como hemos visto en 4.1. (Tabla 2), dirigido y acompañado sobresalen entre los complementos predicativos de coaparición más frecuente con el pseudocopulativo ir.

A la hora de explicar los usos de ir, es indudable que las combinaciones ir dirigido e ir acompañado tienen especial importancia. También presentamos esta frecuencia de coocurrencia a los estudiantes, ya que tiene impacto y puede enfatizar la importancia de estas combinaciones. En la siguiente sección presentamos un ejemplo de material didáctico que tiene en cuenta este aspecto. Además, será de ayuda el hecho de que estos complementos formen clústeres semánticos. Destinado y encaminado se consideran sinónimos de dirigido. Unido, ligado, asociado e incluido lo son para acompañado. Semántica o lógicamente, se espera que el pseudocopulativo ir se combine con cualquier predicativo puesto que tiene poco contenido semántico y es cuasisinónimo de estar. Sin embargo, en realidad, los complementos que se combinan con el pseudocopulativo casi se limitan a los que denotan la dirección y relación concomitante. Este hecho lingüístico puede simplificar la enseñanza del pseudocopulativo ir. A los docentes no nos hace falta señalar un montón de combinaciones de ir y complementos. Sería mucho más eficaz mostrar que dirigido y acompañado se combinan con frecuencia especialmente alta, así como que la mayoría de los complementos que van junto con ir son sinónimos de ellos. Por la convencionalidad, podemos dar explicaciones de los usos desemantizados de manera generalizada. 
En el caso del verbo de apoyo echar, como muestra la Tabla 4, vistazo es el complemento más frecuente (diez veces más que el segundo). Además, vistazo forma un clúster semántico con sus sinónimos vista, ojeada y mirada. Así, el verbo echar está especializado en denotar la acción visual. A la hora de tratar el verbo en el aula, esto es lo que debe indicarse primero. Esto es lo esencial del uso de echar y una pista para inferir la aceptabilidad de la combinación del verbo.

\begin{tabular}{|c|c|c|}
\hline & Complemento eventivo & $\begin{array}{l}\text { Frecuencia de coaparición con } \\
\text { echar }\end{array}$ \\
\hline 1 & Vistazo & 25,656 \\
\hline 2 & Vista & 2,218 \\
\hline 3 & Cuenta & 1,879 \\
\hline 4 & Risa & 1,812 \\
\hline 5 & Cierre & 1,387 \\
\hline 6 & Partida & 1,357 \\
\hline 7 & Ojeada & 1,112 \\
\hline 8 & Mirada & 1,127 \\
\hline 9 & Bronca & 1,037 \\
\hline 10 & Pulso & 602 \\
\hline
\end{tabular}

El verbo de apoyo dar tiene un carácter genérico, pero también muestra una distribución desequilibrada. Como se confirma en la Tabla 5, vuelta y respuesta sobresalen en la frecuencia de coaparición. Estos dos no solo son coapariciones frecuentes sino también son elementos céntricos de los clústeres semánticos que forman. Paso denota movimiento al igual que vuelta. Información, clase y opinión pueden considerarse sinónimos de respuesta. Se podría decir que el verbo de apoyo dar tenía dos funciones principales: denotar movimientos y transferencia de informaciones. 


\begin{tabular}{|c|c|c|}
\hline & Complemento eventivo & $\begin{array}{c}\text { Frecuencia de coaparición } \\
\text { con dar }\end{array}$ \\
\hline 1 & Vuelta & 57,982 \\
\hline 2 & Respuesta & 44,910 \\
\hline 3 & Paso & 29,178 \\
\hline 4 & Comienzo & 19,695 \\
\hline 5 & Cita & 17,927 \\
\hline 6 & Salto & 17,365 \\
\hline 7 & Información & 13,222 \\
\hline 8 & Clase & 13,152 \\
\hline 9 & Opinión & 11,884 \\
\hline 10 & Explicación & 11,442 \\
\hline
\end{tabular}

Hasta las perífrasis de carácter general como tener que $V$, que tiene alta colocabilidad se combinan con unos infinitivos con elevada frecuencia. Véase la Tabla 6.

\begin{tabular}{|c|c|c|}
\hline & Infinitivos & $\begin{array}{l}\text { Frecuencia de coaparición con } \\
\text { tener que }\end{array}$ \\
\hline 1 & Estar & 37,026 \\
\hline 2 & Pagar & 25,004 \\
\hline 3 & Dar & 23,281 \\
\hline 4 & Esperar & 18,856 \\
\hline 5 & Pasar & 16,426 \\
\hline 6 & Dejar & 10,765 \\
\hline 7 & Cambiar & 10,391 \\
\hline 8 & Buscar & 9,372 \\
\hline 9 & Realizar & 9,028 \\
\hline 10 & Llevar & 8,803 \\
\hline
\end{tabular}

Así, se estima que cada uno de los verbos desemantizados tiene combinaciones muy frecuentes y su potencial didáctico es extremadamente alto. Evidentemente nuestros estudios no son los primeros que han mostrado las distribuciones desequilibradas de las coapariciones de los verbos desemantizados. Por ejemplo, Bybee y Eddington (2006), analizando los cuatro "becoming verbs" en español, señalaron que cada pseudocopulativo formaba combinaciones formulaicas con unos pocos complementos y los sinónimos 
de tales complementos se podían combinar con cada pseudocopulativo. Podría decirse que para cada verbo desemantizado había un par de combinaciones especialmente frecuentes y estos eran facilitantes que servían de pistas para inferir su distribución. Es obvio que son los que deben recibir mayor importancia en las aulas.

\subsubsection{Convencionalidad e incompatibilidad}

Desde el punto de vista docente, es también importante señalar con qué clase de complementos los verbos desemantizados no se combinan. Para manejar adecuadamente una palabra, no es suficiente conocer con qué complementos y en qué situación se usa, sino que también es imprescindible tener en cuenta cuándo no es correcto usarla. Por ejemplo, la oración errónea "*puso comienzo a la actividad" fue producida por uno de nuestros estudiantes. Según él, como la combinación poner fin es sumamente común, consideró que comienzo podría usarse con poner. Naturalmente, los nativos no combinan poner y comienzo porque saben inconscientemente que la combinación no es espontanea. Así, a la hora de enseñar los usos de poner, es tan importante enseñar que se pone fin como enseñar que no se pone comienzo. Por esta razón, damos importancia a explicar complementos incompatibles de la manera sistemática. No obstante, es imposible especificar combinaciones inaceptables como poner comienzo utilizando los recursos lexicográficos porque estas obras solo tratan combinaciones aceptables o existentes ${ }^{16}$.

Las combinaciones formulaicas que tratamos en el apartado anterior también pueden servir de pistas para especificar la incompatibilidad. Por ejemplo, la incompatibilidad de poner con comienzo no es cuestión de la semántica, sino se considera una cuestión de convención. La combinación de comienzo

\footnotetext{
${ }^{16}$ En cuanto la falta de la información sobre las combinaciones no posibles, resulta interesante subrayar que, para que un diccionario de ELE resulte realmente pedagógico, debería incorporar también las casuísticas en las que tales combinaciones no son posibles. La eficacia de dicha información dependería de introducir comparativas con algunos lenguajes específicos, lo que ayudaría a ponderar el potencial contrastivo de tales combinatorias verbales. Profundizar en el conocimiento de las combinaciones imposibles, ayudaría a desarrollar soluciones a este déficit.
} 
con dar es tan frecuente que está altamente convencionalizada por eso, poner comienzo suena raro. Recuérdese que la colocación es una combinación frecuente y habitualizada. Por eso, ocurre el bloqueo como en la morfología ${ }^{17}$. Entre los datos presentados en este estudio, aparte de *poner comienzo, se observa el bloqueo colocacional. En 4.1., confirmamos que entre los complementos de ir como pseudocopulativo, los que denotan "dirección” y "relación concomitante" son los más frecuentes y según nuestro análisis en el corpus, estos complementos se combinan raramente con otros pseudocopulativos. Se supone que la combinación de ir con estos complementos está altamente convencionalizada y por eso no suenan raros cuando coaparecen con otros pseudocopulativos. Del mismo modo, los sustantivos que denotan "movimientos sin meta" y "comienzo" se combinan con dar y, al mismo tiempo, no pueden ser objeto directo de otros verbos de apoyo a pesar de que dar y los otros verbos están desemantizados y se parecen en su escasa carga semántica. Vistazo es el objeto directo de echar extremadamente frecuente (cf. 5.2.) pero ya confirmamos que era muy poca su combinación con otros verbos de apoyo. En Bybee y Eddington (2006) también se presenta este bloqueo. Como hemos señalado, este es un estudio sobre los cuatro "becoming verbs" en el español hacerse, quedar(se), volverse y ponerse y según las autoras, excepto de hacerse, para cada pseudocopulativo, hay complementos extremadamente frecuentes y tales complementos no se combinan con otros pseudocopulativos. A modo de ejemplo, las autoras defienden que volverse loco es una colocación muy frecuente y loco se combina raramente con los otros pseudocopulativos ${ }^{18}$.

\footnotetext{
${ }^{17}$ Laca (1993) pone robador como un ejemplo de bloqueo. Según la autora, la palabra es poco común porque ya existe ladrón. La existencia de la palabra ladrón bloquea la derivación de robador.

${ }^{18}$ Del corpus que utilizaron las autoras, se sacó un caso de la combinación de quedarse y loco; 17) Bueno y (el precio de) las Ray Ban me quedé loca (p. 338). Las autoras defienden que, en este caso, como el significado de adjetivo loca se asemeja a sorprendida se combina con quedarse puesto que la combinación del pseudocopulativo y complementos que denotan la sorpresa está convencionalizada.
} 
Los complementos que coaparecen con más frecuencia con un verbo suelen presentar, en cambio, escasa frecuencia combinatoria con otros verbos sinónimos. Teniendo en cuenta la importancia de la cuestión "con qué palabras no se puede usar el verbo", examinamos la compatibilidad de tales complementos y, en la mayoría de los casos, se confirma que su combinación con los cuasisinónimos es muy escasa. Vamos especificando así los complementos incompatibles y los reflejamos en la enseñanza de los usos de los verbos. De esta manera, las coapariciones son útiles en dos sentidos; son útiles porque reflejan la tipicidad de los verbos y sugieren los tipos semánticos de los complementos incompatibles con sus cuasisinónimos. Cabrá enfatizar la importancia de esta doble utilidad de los complementos que forman expresiones formulaicas. Dando prioridad a estos aspectos, explicamos los usos desemantizados de ir de la manera siguiente:

$$
\text { Ir の脱意味化用法 }
$$

'El uso desemantizado de ir'

Ir も形容詞や過去分詞といった叙述性の高い語と共起した際に脱意味化し ます。この場合、以下のょうに estar の類義語のようになります。 'I $r$ también se desemantiza cuando se combina con palabras predicativas como adjetivos y participios pasados. En este caso, su función se asemeja a la de estar.'

\section{Hoy ella va muy elegante.}

脱意味化した ir には特に共起することの多い補語が存在します。以下の リストを見てみましょう。右側の数字は形容詞と過去分詞が ir と共起し た回数を示しています。

'Algunos complementos coocurren con ir desemantizado con especial frecuencia. Veamos la siguiente lista. Los números de la derecha son la frecuencia de que el adjetivo y el participio pasado coocurren con ir.'

\begin{tabular}{|l|l|}
\hline Dirigido & 25,176 \\
\hline Acompañado & 21,928 \\
\hline Destinado & 10,323 \\
\hline Unido & 4,652 \\
\hline Encaminado & 4,263 \\
\hline Vestido & 3,839 \\
\hline Ligado & 2,562 \\
\hline Asociado & 2,183 \\
\hline Precedido & 1,852 \\
\hline Incluido & 1,496 \\
\hline
\end{tabular}


特に、 dirigido と acompañado が高い頻度で ir と用いられることがお判り でしょうか。さらに、 dirigido の類義語、 destinado, encaminadoもリスト 内にあります。また、 unido, ligado, asociado, incluido は acompañado の類 義語といえるでしょう。このょうに、脱意味化した ir は方向性と付帯関 係を表すことに特化しています。

'En particular, puedes notar que dirigido y acompañado se usan frecuentemente con ir. Además, los sinónimos de dirigido, destinado y encaminado también están en la lista. Además, unido, ligado, asociado e incluido son sinónimos de acompañado. Así, el ir desemantizado se especializa en expresar la dirección y la relación concomitante.'

脱意味化したir るがir とは共起することがほぼない語が多く存在します。triste, contento, feliz といった心理状態を表すものや、presente, disponible といつた形容 詞は estar と極めて高い頻度で共起する一方、ir とは共起しません。Hoy voy muy contento. といった言い回しは避けましょう。

'Aunque he dicho que $i r$ desemantizado es un sinónimo de estar, hay muchas palabras que coaparecen con estar pero casi nunca con $i$. Los que denotan estados mentales como triste, contento, feliz, y los adjetivos como presente y disponible coocurren muy frecuentemente con estar pero muy poco con $i$. Es mejor evitar frases como Hoy voy muy contento.'

\section{CONCLUSIÓN Y T'RABAJO FU'T'URO}

A lo largo de este estudio hemos señalado la importancia y lo difícil de los usos desemantizados verbales. También hemos propuesto que la formulaicidad de tales usos puede facilitar tanto el aprendizaje como la enseñanza.

En este último apartado, teniendo en cuenta el análisis que hemos hecho, nos gustaría presentar nuestro proyecto de trabajo futuro y algunas sugerencias para la mejora de la enseñanza del vocabulario en español. En concreto, consideramos necesario y provechoso realizar un estudio lexicográfico exhaustivo de los usos de los verbos. Eso nos permitiría aprovechar la formulaicidad de la lengua para lograr mayor eficacia en la enseñanza del vocabulario.

Según lo que vemos, la formulaicidad de los usos desemantizados no suele tratarse en los recursos lexicográficos o gramáticos. Por ejemplo, en el DLE, la entrada de ir presenta dos acepciones que tratan del uso pseudocopulativo, pero ninguna de las dos se refiere a las combinaciones más frecuentes que presentamos en la Tabla 2. 
11. intr. U., con ciertos adjetivos o participios pasivos, para expresar irónicamente lo contrario de lo que estos significan. Vas apañado.

12. intr. Junto con el participio de los verbos transitivos, significa padecer su acción, y con el de los reflexivos, hallarse en el estado producido por ella. Ir vendido. Ir arrepentido. (DLE, 2021 [2014], s.v. ir).

En la NGLE, la explicación es mucho más detallada. Se presentan las combinaciones de ir con complementos de tipo movimiento y relación concomitante.

Aspecto externo: acicalado, arreglado, con sombrero

Interpretación concomitante: acompañado, adornado, descrito

Constancia: escrito, firmado, sellado

Participios de verbos que denotan dirección: destinado, dirigido, enfocado (NGLE, $2009,38.5 y, z)$

No obstante, desde el punto de vista docente, sería más práctico si hubiera una mención de que los complementos de "interpretación concomitante" y "dirección" son mucho más frecuentes que los otros y son los que reflejan la tipicidad del pseudocopulativo.

En el caso de echar, las explicaciones tampoco son suficientes. En el DLE, la mención a su uso del verbo de apoyo se limita a 19. tr. Hacer cálculos, cuentas y la NGLE explica que los complementos eventivos más típicos del verbo son el cerrojo, una cabezada, una carrera, una partida, a pesar de que, como hemos señalado, echar, en realidad, es un verbo de apoyo especializado en denotar acciones visuales.

Cada verbo desemantizado suele tener combinaciones extremadamente frecuentes. La distribución de los complementos no es equilibrada. Esta formulaicidad es lo que ayuda el aprendizaje de los estudiantes ${ }^{19}$, pero, como hemos visto, parece que no está suficientemente reflejada en los materiales de los

${ }^{19}$ Casenhiser y Goldberg (2005) realizaron un experimento sobre la adquisición de cinco verbos nuevos e inventados como moopo y vako. A un grupo de niños se los presentaron con la frecuencia desequilibrada (moopo 4 veces y presentaron una vez cada uno de los otros verbos), mientras que al otro grupo se los presentaron de la manera equilibrada. Los resultados mostraron que los niños del primer grupo adquirieron los verbos nuevos con mayor eficacia que los niños del segundo grupo. Por lo tanto, se sugiere que una frecuencia excepcionalmente alta también facilita el aprendizaje general de esos elementos recurrentes. 
libros de texto y diccionarios. O sea, puede que todavía no sepamos bien cómo están usándose las palabras y no conozcamos la realidad de los usos de los verbos. Es muy posible que haya discrepancias entre cómo se usan realmente las palabras y lo que imaginamos sobre los verbos. Nos gustaría defender que las investigaciones sobre este aspecto de las palabras serían trabajo muy fructífero tanto para la léxicología como para la enseñanza del vocabulario.

\section{BIBLIOGRAFIA}

Allan, Q. (1998). Delexical verbs and degrees of desemanticization. WORD, 49(1), 1-17. https://doi.org/10.1080/00437956.1998.11673876

Alonso Ramos, M. (2004). Las construcciones con verbo de apoyo. Visor Libros.

Butt, M. J. (2014). The Light Verb Jungle: Still Hacking Away. En M. Amberber, B. Baker \& M. Harvey (eds.), Complex predicates in cross-linguistic perspective. https://doi. org/10.1017/CBO9780511712234.004

Bybee, J., \& Eddington, D. (2006). A Usage-Based Approach to Spanish Verbs of "Becoming". Language, 82(2), 323-355. https://doi.org/10.1353/lan.2006.0081

Casenhiser, D. \& Goldberg, A. E. (2005). Fast mapping between a phrasal form and meaning. Developmental science, 8(6), 500-508. https://doi.org/10.1111/j.1467-7687. 2005.00441.x

De Miguel, E. (2009). En qué consiste ser el verbo de apoyo. En M. ${ }^{a}$ V. Escandell Vidal, M. Leonetti \& C. Sánchez López (Eds.), 60 problemas de gramática dedicados a Ignacio Bosque (pp. 139-146). Akal.

Del Burgo, M. (1998). Tener, coger, poner y dar como verbos de soporte. Interlingüística, 9 , 179-184.

$D L E=$ Real Academia Española. (2014). Diccionario de la lengua española, 23a edición. Espasa. https://dle.rae.es/

García Fernández, L. (2006). Diccionario de perífrasis verbales. Gredos.

Grimshaw, B. (1990). Argument structure. MIT Press.

Herrero Ingelmo, J. L. (2003). Los verbos soportes: ¿gramática o léxico? En F. Sánchez Miret (coord.), Actas Del XXIII Congreso Internacional de Lingüústica y Filología Románica, Vol. 2 (pp. 453-468). Max Niemeyer Verlag. https://doi.org/10.1515/9783110946260-041

Hirasawa, S. (2019). What is means to know the meaning of the preposition By: Polysemy as usage variation. Kuroshio.

Koike, K. (1992). Locución verbal y verbo compuesto. Hispánica, 36, 89-104. https://doi. org/10.4994/hispanica1965.1992.89 
Kuteva, T. (2001). Auxiliation An Enquiry into the Nature of Grammaticalization. Oxford University Press.

Laca, B. (1993). Las nominalizaciones orientadas y los derivados españoles en"-dor" y"-nte". En S. Varela (ed.). La formación de las palabras (pp. 180-204). Taurus.

Lehmann, C. (1995). Thoughts on grammaticalization. Lincom Europa.

Lexical Computing (s.f.). Sketch Engine. European Spanish web 2011 (euesTen Ten). [software] https://cutt.ly/SR1ti6z

Millet, A. (1912). L'évolution des formes grammaticales. Scientia, 12, 130-148.

Mitatou, Z. (2011). Las construcciones del verbo dar en la enseñanza del español como lengua extranjera (E/LE). RedELE, 23, 1-64.

Montagna, D. (2015). Eventos y entidades que se pueden echar: combinatoria léxica y representación del significado de un verbo polisémico [Tesis Doctoral. Universidad Autónoma de Madrid]. Repositorio Institucional de la UNAM. https://cutt.ly/oR1eHPw

Morimoto, Y. \& Lucero Pavón, M. V. (2007). Los verbos pseudo-copulativos del español. Arco Libros.

$N G L E=$ Real Academia Española/Asociación de Academias de la Lengua Española. (2009). Nueva Gramática de la lengua española. Espasa Calpe.

Resnik, G. (2010). Los nombres eventivos no deverbales en español [Tesis doctoral. Universidad Pompeu Fabra]. Repositori Digital UPF. https://cutt.ly/NR1eYd7

Sánchez Rufat, A. (2015). El verbo dar en el español escrito de aprendientes de L1 inglés. estudio comparativo entre hablantes no nativos y hablantes nativos basado en corpus [Tesis Doctoral. Universidad de Extremadura]. Redined. Red de información educativa. https://cutt.ly/1R1e448

Traugott, E. C. \& Heine, B. (eds). (1991). Approaches to Grammaticalization. Benjamins. https://doi.org/10.1075/tsl.19.1

Tsutahara, R. (2018a). Las colocaciones "verbo de apoyo + nombre eventivo": un estudio comparativo español-inglés. Hispánica, 62, 27-51. https://doi.org/10.4994/hispanica.2018.27

Tsutahara, R. (2018b). Una clase sobre los usos de los verbos habituales basada en un índice marcador de la dificultad de aprendizaje. Foro de Profesores de E/LE, 14, 365-374. https://doi.org/10.7203/foroele.14.13362

Tsutahara, R. (2019). Sobre el verbo echar como verbo de apoyo. Studia romanica, 52, 1-10.

Tsutahara, R. (2020). Un estudio comparativo de ir y go como verbos semicopulativos. Hispánica, 64, 51-77. https://doi.org/10.4994/hispanica.2020.51

Wierzbicka, A. (1982). Why Can You Have a Drink When You Can't *Have an Eat? Language, 58(4), 753-799. https://doi.org/10.2307/413956 